\title{
The PI3K/Akt/mTOR axis in head and neck cancer: functions, aberrations, cross-talk, and therapies
}

\author{
R Vander Broek ${ }^{1,2,3}$, S Mohan ${ }^{1,2}$, DF Eytan ${ }^{1,2}$, Z Chen $^{1}$, C Van Waes ${ }^{1}$ \\ ${ }^{1}$ Tumor Biology Section, Head and Neck Surgery Branch, National Institute on Deafness and Other Communication Disorders, \\ National Institutes of Health, Bethesda, MD; ${ }^{2}$ Medical Research Scholars Program, National Institutes of Health, Bethesda, MD; \\ ${ }^{3}$ School of Dentistry, University of Michigan, Ann Arbor, MI, USA
}

\begin{abstract}
Head and neck squamous cell carcinoma (HNSCC) is one of the most morbid, mortal, and genetically diverse malignancies. Although HNSCC is heterogeneous in nature, alterations in major components of the $\mathrm{PI} 3 \mathrm{~K} /$ Akt/mTOR pathway are consistently observed throughout the majority of HNSCC cases. These alterations include genetic aberrations, such as mutations or DNA copy number variations, and dysregulation of mRNA or protein expression. In normal physiology, the PI3K/Akt/ mTOR axis regulates cell survival, growth, and metabolism. However, alterations in this pathway lead to the malignant phenotype which characterizes HNSCC, among many other cancers. For this reason, both pharmaceutical companies and academic institutions are actively developing and investigating inhibitors of PI3K, Akt, and $m$ TOR in preclinical and clinical studies of HNSCC. Many of these inhibitors have shown promise, while the effects of others are tempered by the mechanisms through which HNSCC can evade therapy. As such, current research aimed at elucidating the interactions between PI3K/Akt/mTOR and other important signaling pathways which may drive resistance in HNSCC, such as p53, NF- $\kappa \mathrm{B}$, and MAPK, has become a prominent focus toward better understanding how to most effectively treat HNSCC.
\end{abstract}

Oral Diseases (2015) 2I, 8I5-825

Keywords: head and neck cancer; PI3K; Akt; mTOR; NF- $\kappa \mathrm{B}$; p53

\section{Introduction}

Head and neck cancer is the sixth most common cancer worldwide and has a 5-year morbidity rate of $\sim 50 \%$

Correspondence: Carter Van Waes, MD, PhD or Zhong Chen, MD, PhD, National Institute on Deafness and Other Communication Disorders, National Institutes of Health, Building 10/CRC Rm 4-2732 or Rm 5D55, 10 Center Dr., Bethesda, MD 20892, USA. Tel: 301402 4216, Fax: 301 402 1140, E-mails: vanwaesc@nidcd.nih.gov or chenz@nidcd.nih.gov Received 23 October 2013; revised 3 November 2013; accepted 3 November 2013
(Siegel et al, 2013). The histological diagnosis of head and neck squamous cell carcinoma (HNSCC) accounts for over $95 \%$ of all clinical cases of head and neck cancer and is limited anatomically to one of five primary sites: oral cavity, oropharynx, nasopharynx, hypopharynx, or larynx (Leemans et al, 2011). In terms of genetic alterations, HNSCC is one of the most heterogeneous of all cancers (Vogelstein et al, 2013). However, The Cancer Genome Atlas (TCGA; cancergenome.nih.gov) and other studies recently revealed that the majority of HNSCC possess alterations in the PI3K/Akt/mTOR pathway (Grandis et al, 2012; Hayes et al, 2013), a critical regulatory axis for cell growth, survival, motility, and metabolism in both normal physiology and cancer.

Phosphoinositide 3-kinase (PI3K), is composed of two subunits - an $85-\mathrm{kDa}$ regulatory subunit and a $110-\mathrm{kDa}$ catalytic subunit. It is activated in response to somatic mutation, stimulated receptor tyrosine kinases (RTKs) such as epidermal growth factor receptor (EGFR) and insulin-like growth factor receptor 1 (IGF-1R), or G-protein-coupled receptors (GPCRs). PI3K catalytic subunit alpha isoform $(P I K 3 C A)$, the gene that programs for the $\mathrm{p} 110 \alpha$ isoform of PI3K, is one of the most frequently mutated and amplified oncogenes in human cancers (Yuan and Cantley, 2008), including HNSCC. In normal physiology, PI3K is regulated by the tumor suppressor, Phosphatase and tensin homolog (PTEN). However, inactivating mutation or loss of PTEN is a frequent alteration in cancer and leads to hyperactivity of the PI3K pathway (Courtney et al, 2010). Protein kinase B (Akt) and mammalian target of rapamycin (mTOR) are effector proteins downstream of $\mathrm{PI} 3 \mathrm{~K}$ and also play important roles in carcinogenesis. Together, the members of the PI3K/Akt/mTOR axis interact with and contribute to the regulation of several other signaling molecules in HNSCC, including tumor suppressor, tumor protein p53 [p53 (TP53)], nuclear factor-kappa $\mathrm{B}(\mathrm{NF}-\kappa \mathrm{B})$, and mitogen-activated protein kinase (MAPK)/extracellular signal-regulated kinase (ERK) (Figure 1). For these reasons, there has been a surge in the development and use of pharmacologic inhibitors targeting PI3K, Akt, and mTOR for cancers such as HNSCC (Table 1). Initial preclinical and clinical studies indicate 


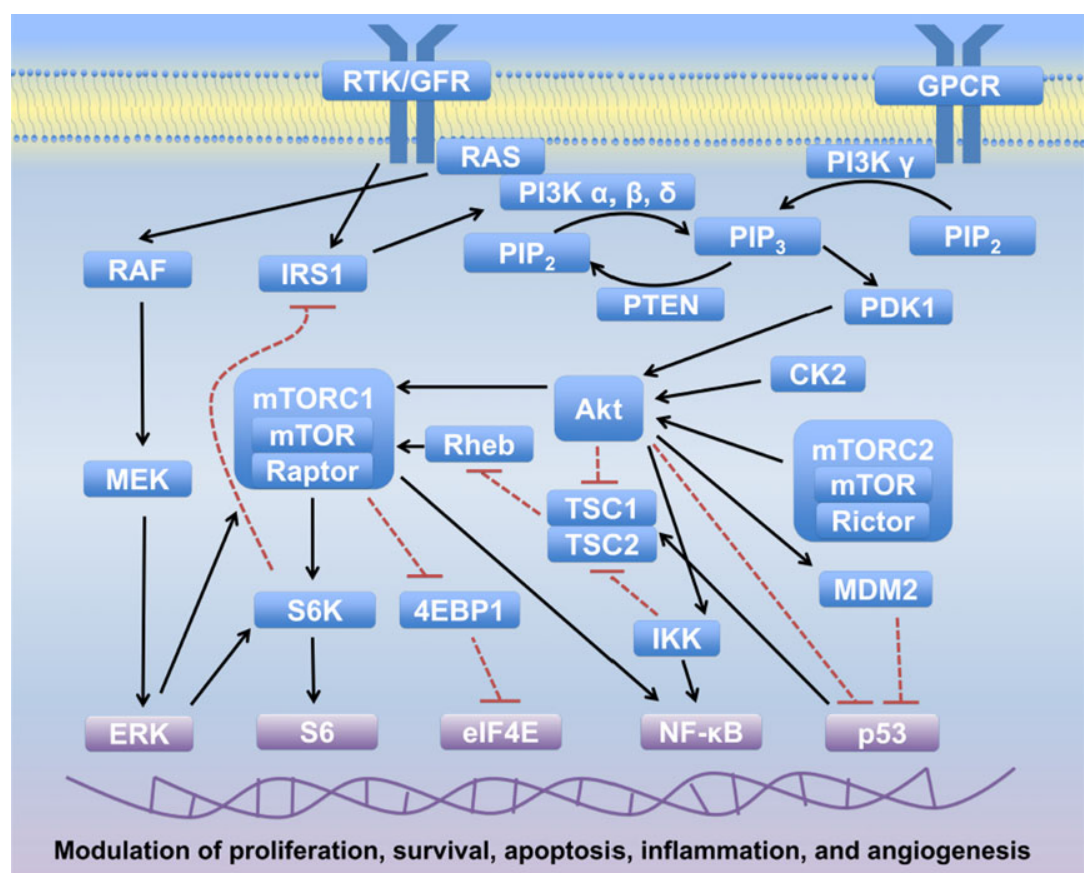

Figure 1 Interactive signaling of PI3K/Akt/ mTOR and other pathways. Relationships between well-characterized molecular signaling routes in HNSCC (EGFR/PI3K/PTEN/Akt/ mTOR, RAS/RAF/MEK/ERK, IKK/NF- $\kappa$ B, and MDM2/p53) are shown by black arrows (activating interactions) and dashed red lines (negative regulation). PI3K/Akt/mTOR activation or inhibition ultimately regulates the activity of many kinases and transcription factors (purple) important in the nuclear control of cell survival and the malignant phenotype promise for PI3K and mTOR inhibitors to benefit patients with HNSCC.

\section{EGFR/PI3K/Akt/mTOR signaling in normal physiology}

The EGFR/PI3K/Akt/mTOR signaling cascade is critical to cell growth, development, survival, and differentiation. Epidermal growth factor receptor (EGFR), also known as ErbB-1 or HER1, contains an extracellular ligand-binding domain, a hydrophobic transmembrane portion, and a cytoplasmic domain containing tyrosine kinase activity and multiple phosphorylation sites (Kalyankrishna and Grandis, 2006; Normanno et al, 2006; Freudlsperger et al, 2011). At least 30 ligands of the four ErbB family members have been characterized (Rogers et al 2005). Ligand binding triggers receptor activation through dimerization and auto- or cross-phosphorylation of the tyrosine kinase domains ( $\mathrm{Lu}$ et al, 2012), which initiates EGFR signal transduction through multiple intracellular pathways, including the PI3K/Akt/mTOR pathway.

There are three classes of PI3Ks (I, II, and III), classified by structure and substrate preference. Class I PI3Ks, the subject of this review, are divided into subclasses IA and IB (Vanhaesebroeck et al, 2012). While initially postulated that IA enzymes are activated by RTKs, and IB enzymes are stimulated through GPCRs, recent work shows crossover in these stimuli (Katso et al, 2001). PI3K IA catalytic subunits include $\mathrm{p} 110 \alpha(P I K 3 C A), \mathrm{p} 110 \beta$, and $\mathrm{p} 110 \delta$ - all of which contain an N-terminal p85 regulatory subunit-binding domain and a Ras-binding domain (Domin and Waterfield, 1997; Fruman et al, 1998). p110 $\alpha$ and p110 $\beta$ are ubiquitously expressed, while p $110 \delta$ is mainly found in leukocytes, as it is a key player in lymphoid differentiation and development (Vanhaesebroeck et al, 2010). PI3K class IB includes the catalytic p110 $\gamma$ subunit, which is similar to the p110 $\alpha-\delta$ subunits, but does not contain a p85-binding site (Katso et al, 2001). Activated EGFR recruits and activates class IA PI3K at the membrane through direct binding of the Src homology 2 domains of $\mathrm{p} 85$ with the phosphotyrosine residues of the activated receptor (Engelman, 2009). Upon activation, the catalytic p110 subunit phosphorylates phosphatidylinositol-4,5-bisphosphate $\left(\mathrm{PIP}_{2}\right)$, converting it into phosphatidylinositol-3,4,5-trisphosphate $\left(\mathrm{PIP}_{3}\right)$. Tumor suppressor PTEN antagonizes PI3K function by dephosphorylating $\mathrm{PIP}_{3}$ to regenerate $\mathrm{PIP}_{2}$. $\mathrm{PIP}_{3}$ functions as a second messenger with binding sites for signaling proteins with pleckstrin homology $(\mathrm{PH})$ domains including 3-phosphoinositide-dependent protein kinase-1 (PDK1) and Akt (protein kinase B) (Liu et al, 2009).

Akt is a serine/threonine protein kinase with three isoforms (Akt1, Akt2, and Akt3) (Bellacosa et al, 1991), which require phosphorylation for activation (Scheid and Woodgett, 2001). Akt's N-terminal region contains a PH domain that interacts with $\mathrm{PI} 3 \mathrm{~K}$ products and initiates its recruitment to the plasma membrane, conformational change, and subsequent phosphorylation. Upon binding with $\mathrm{PIP}_{3}$, Akt is phosphorylated at three different sites: threonine 308 stabilizing the activation loop of the catalytic kinase domain by Phosphoinositide dependent kinase (PDK1) (Vivanco and Sawyers, 2002), serine 473 in the hydrophobic $\mathrm{COOH}$-terminal domain by mTORC2 (mTOR complex 2) (Sarbassov et al, 2005), and serine 129 between the $\mathrm{PH}$ and catalytic domains by casein kinase 2 (CK2) (Di Maira et al, 2005). Activated Akt has multiple downstream targets involved in cell survival, growth, proliferation, angiogenesis, metabolism, and migration (Manning and Cantley, 2007).

A major downstream effector of Akt is mTOR, also a serine/threonine protein kinase, and the catalytic subunit of mTOR complex 1 (mTORC1). mTORC1 regulates protein translation through phosphorylation of protein synthe- 
Table 1 Currently ongoing clinical trials of PI3K/Akt/mTOR inhibitors targeting HNSCC and solid tumors. All ongoing clinical trials of PI3K/Akt/ mTOR inhibitors that include any patients with HNSCC are listed, unless noted otherwise. The three most common adverse events associated with each agent are presented in order of frequency reported, to date. Clinical trial IDs are indexed by http://clinicaltrials.gov (National Institutes of Health)

\begin{tabular}{|c|c|c|c|c|c|}
\hline Drug (company) & Combination & Status & Clinical trial ID & Condition & Adverse events \\
\hline \multicolumn{6}{|l|}{ PI3K Inhibitors } \\
\hline \multirow{2}{*}{$\begin{array}{l}\text { BKM120 } \\
\text { (Novartis, East } \\
\text { Hanover, NJ, USA) }\end{array}$} & Cetuximab & Phase I/II & NCT01816984 & Recurrent or metastatic HNSCC & \multirow{2}{*}{$\begin{array}{l}\text { Rash, hyperglycemia, } \\
\text { diarrhea }\end{array}$} \\
\hline & Single agent & Phase II & NCT01737450 & $\begin{array}{l}\text { Metastatic, recurrent, or progressive } \\
\text { HNSCC }\end{array}$ & \\
\hline \multirow{2}{*}{$\begin{array}{l}\text { PX-866 } \\
\text { (Oncothyreon, } \\
\text { Seattle, WA, USA) }\end{array}$} & Cetuximab & Phase I/II & NCT01252628 & $\begin{array}{l}\text { Incurable, progressive, recurrent or } \\
\text { metastatic HNSCC }\end{array}$ & \multirow[t]{2}{*}{$\begin{array}{l}\text { Diarrhea, nausea, } \\
\text { vomiting }\end{array}$} \\
\hline & Docetaxel & Phase I/II & NCT01204099 & $\begin{array}{l}\text { Locally advanced, recurrent or metastatic } \\
\text { HNSCC }\end{array}$ & \\
\hline \multirow{2}{*}{$\begin{array}{l}\text { BYL719 } \\
\text { (Novartis) }\end{array}$} & Cetuximab & Phase Ib/II & NCT01602315 & Recurrent or metastatic HNSCC & \multirow{2}{*}{$\begin{array}{l}\text { Nausea, hyperglycemia, } \\
\text { diarrhea }\end{array}$} \\
\hline & Single agent & Phase Ia & NCT01219699 & $\begin{array}{l}\text { Advanced solid malignancies, including } \\
\text { HNSCC, with an alteration of PIK3CA }\end{array}$ & \\
\hline \multicolumn{6}{|l|}{ mTOR Inhibitors } \\
\hline \multirow{6}{*}{$\begin{array}{r}\text { Everolimus } \\
\text { (Novartis) }\end{array}$} & Single agent & Phase II & NCT01051791 & HNSCC & \multirow[t]{6}{*}{ Rash, mucositis, fatigue } \\
\hline & Single agent & Phase II & NCT01133678 & HNSCC & \\
\hline & $\begin{array}{l}\text { Carboplatin, } \\
\text { cetuximab }\end{array}$ & Phase I/II & NCT01283334 & Advanced HNSCC & \\
\hline & $\begin{array}{l}\text { Carboplatin, } \\
\text { paclitaxel }\end{array}$ & Phase I/II & NCT01333085 & $\begin{array}{l}\text { Unresectable or inoperable locally } \\
\text { advanced HNSCC }\end{array}$ & \\
\hline & Cetuximab & Phase I & NCT01637194 & Metastatic or recurrent HNSCC & \\
\hline & Erlotinib & Phase II & NCT00942734 & HNSCC & \\
\hline $\begin{array}{l}\text { Rapamycin } \\
\text { (Pfizer, New York, } \\
\text { NY, USA ) }\end{array}$ & Single agent & Phase I/II & NCT01195922 & Previously untreated HNSCC & $\begin{array}{l}\text { Hyperglycemia, nausea, } \\
\text { anemia }\end{array}$ \\
\hline \multirow{3}{*}{$\begin{array}{l}\text { Temsirolimus } \\
\text { (Pfizer) }\end{array}$} & Single agent & Phase II & NCT01172769 & HNSCC & \multirow{3}{*}{$\begin{array}{l}\text { Rash, mucositis, mood } \\
\text { disturbance }\end{array}$} \\
\hline & Cetuximab & Phase II & NCT01256385 & Recurrent or metastatic HNSCC & \\
\hline & $\begin{array}{l}\text { Carboplatin, } \\
\text { paclitaxel }\end{array}$ & Phase I/II & NCT01016769 & HNSCC & \\
\hline \multicolumn{6}{|l|}{ PI3K/mT0R Dual Inhibitors } \\
\hline $\begin{array}{l}\text { BEZ235 } \\
\text { (Novartis) }\end{array}$ & Everolimus & Phase Ib & NCT01508104 & $\begin{array}{l}\text { Metastatic or unresectable advanced } \\
\text { solid tumors }\end{array}$ & Fatigue, nausea, diarrhea \\
\hline $\begin{array}{l}\text { PF-04691502 } \\
\text { (Pfizer) }\end{array}$ & Single agent & Phase I & NCT00927823 & $\begin{array}{l}\text { Advanced solid tumors including } \\
\text { HNSCC }\end{array}$ & Fatigue, nausea, vomiting \\
\hline \multirow[t]{2}{*}{$\begin{array}{l}\text { PF-05212384 } \\
\text { (Pfizer) }\end{array}$} & $\begin{array}{l}\text { Docetaxel, cisplatin, } \\
\text { dacomitinib }\end{array}$ & Phase I & NCT01920061 & Advanced solid tumors ${ }^{\mathrm{a}}$ & \multirow[t]{2}{*}{ Mucositis, nausea, fatigue } \\
\hline & PD-901, irinotecan & Phase I & NCT01347866 & Advanced solid tumors ${ }^{\mathrm{a}}$ & \\
\hline $\begin{array}{l}\text { SAR245409 } \\
\text { (Sanofi, Bridgewater, } \\
\text { NJ, USA) }\end{array}$ & Pimasertib & Phase I & NCT01390818 & Advanced solid tumors ${ }^{\mathrm{a}}$ & Rash, diarrhea, fatigue \\
\hline \multicolumn{6}{|l|}{ Akt Inhibitors } \\
\hline $\begin{array}{l}\text { MK2206 } \\
\text { (Merck, Whitehouse } \\
\text { Station, NJ, USA) }\end{array}$ & Single Agent & Phase II & NCT01349933 & Recurrent or metastatic HNSCC & Rash, nausea, pruritis \\
\hline
\end{tabular}

HNSCC, Head and neck squamous cell carcinoma.

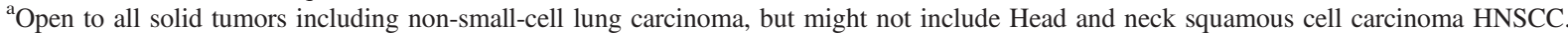

sis components based on growth factor and nutrient availability (Hennessy et al, 2005). mTORC1 and mTORC2 are structurally and functionally unique complexes; mTORC1 contains raptor (rapamycin-sensitive adaptor protein of mTOR), while mTORC2 binds rictor (rapamycin-insensitive companion protein of mTOR). Activation of mTORC1 occurs through Akt-mediated inactivation of the tuberous sclerosis complex (TSC). The TSC consists of a heterodimer of tumor suppressor proteins hamartin (TSC1) and tuberin (TSC2) and antagonizes mTOR signaling by inhibiting the Ras-like small GTPase, Rashomolog enriched in brain (Rheb), a direct regulator of mTOR signaling (Li et al, 2004; Pan et al, 2004). Wellcharacterized targets of mTORC1 include ribosomal protein S6 kinase (RPS6K or S6K) and eukaryote initiation factor 4E-binding protein 1 (EIF4EBP1 or 4EBP1), both key regulators of protein translation. S6K phosphorylation of the S6 protein increases translation of ribosomal proteins and translation regulators (Meyuhas, 2000; Inoki et al, 2005). 4EBP1, a translation inhibitor, binds and inhibits eukaryotic translation initiation factor 4E (eIF-4E), which initiates translation (Gingras et al, 1999). mTORC2 regulates actin cytoskeletal reorganization and serves as a hydrophobic motif kinase for Akt at serine 473 (Bhaskar and Hay, 2007).

\section{EGFR/PI3K/Akt/mTOR pathway aberrations in HNSCC}

Recent developments in deep sequencing of tumor tissues have paved a powerful path for discovery of the most frequent genetic alterations in HNSCC. Unbiased highthroughput approaches have revealed that PIK3CA is one of the most commonly mutated and amplified genes in the 
protein-coding human HNSCC genome (Agrawal et al, 2011; Stransky et al, 2011), which validates earlier PIK3CA-targeted studies (Okami et al, 1998; Kozaki et al, 2006; Qiu et al, 2006; Murugan et al, 2008; Cohen et al, 2011; Morris et al, 2011). PIK3CA missense mutations are concentrated in three 'hotspots' on chromosome $3 q 26$ (H1047R, E545K, and E542K) known to affect constitutive PI3K activity (Samuels et al, 2004). Recent mutation analysis of 279 patients with HNSCC by TCGA has provided evidence that $P I K 3 C A$ mutations are among the most frequent mutations in HNSCC (18\% in HPV-negative cancers and $37 \%$ in HPV-positive cancers) (Grandis et al, 2012; Hayes et al, 2013). Altogether, genetic changes (mutation or DNA copy number variation) in major components of the PI3K pathway are represented in $66 \%$ of the TCGA HNSCC cases studied (Figure 2). When including changes in mRNA expression, this statistic jumps to over 90\% (http://www.cbioportal.org), with alterations in one component of the pathway often being mutually exclusive with changes in a different component. PIK3CA DNA copy number is amplified in $20 \%$ of TCGA cases and mRNA expression is upregulated in $52 \%$ the TCGA tumors (Iglesias-Bartolome et al, 2013), with reduced PTEN expression in $\sim 30 \%$ of another HNSCC cohort (Squarize et al, 2013). As a whole, the cumulative changes in $\mathrm{PI} K \mathrm{~K} / \mathrm{Akt} / \mathrm{mTOR}$ and molecules that communicate with this axis are represented at a significant rate in HNSCC. Consequently, it serves as an attractive target for molecular-oriented therapy.

A recent analysis showed that druggable events (copy gain with increased expression or activating mutation) associated with the PIK3CA or $A K T 1 / 2 / 3$ loci could be targeted in $12 / 35$ (34\%) HNSCC tumors sequenced (Pickering et al, 2013). In a functional test of the drugga- bility of PIK3CA mutations in HNSCC patient tumor grafts, mutated rather than wild-type $P I K 3 C A$ conferred a greater sensitivity to the PI3K/mTOR inhibitor BEZ-235 (Lui et al, 2013). The same result held true for the PI3K inhibitor PX-866 in HNSCC patient tumor grafts (Keysar et al, 2013). Thus, the predilection of PI3K inhibitors activity for HNSCC with PIK3CA activating mutations provides one rationale for using $P I K 3 C A$ mutational status as a predictor of treatment selection. When considering the importance of human papilloma virus (HPV) oncoproteins E6 and E7 in the etiology of a subset of HNSCC, and the association of HPV with PI3K pathway mutations, this rationale is strengthened. In a directed analysis of 15 genes in 64 HNSCC tumors, PIK3CA mutation was the most abundant mutation, found at a much higher frequency in the oropharynx than in any other primary site (McBride et al, 2013). This observation is consistent with a putative association between higher rates of HPV infection in oropharynx than in other head and neck cancer anatomic sites (Gillison et al, 2000), and higher rates of PIK3CA mutation in HPV+ HNSCC than in HPVHNSCC (Lui et al, 2013; Nichols et al, 2013).

\section{PI3K/Akt/mTOR aberrations promote the malignant phenotype}

Functionally, aberrations in the PI3K/Akt/mTOR pathway are associated with many of the malignant characteristics of HNSCC, including immune suppression and inflammation, angiogenesis, survival, invasion, and metastasis. Inflammation, in specific, regulates many of these processes simultaneously (Grivennikov et al, 2010). In contrast to ubiquitously expressed PI3K p110- $\alpha$ and $-\beta$ isoforms, $\mathrm{p} 110-\delta$ is mainly present in leukocytes and

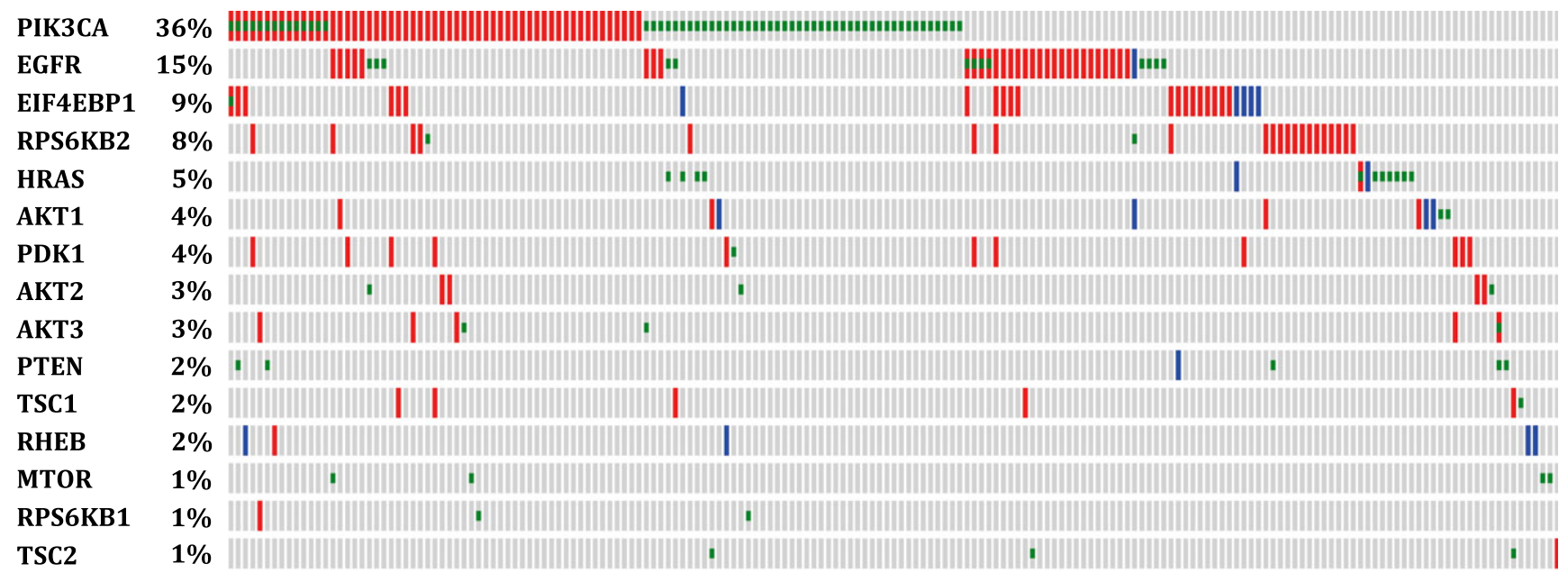

\section{| Amplification | Homozygous deletion | Mutation}

Figure 2 The frequency of genetic alterations of signaling molecules involved in PI3K pathway. The genetic data were obtained from cBioPortal for Cancer Genomics (http://www.cbioportal.org), where the data from The Cancer Genome Atlas (TCGA) project were deposited. The data were collected from 279 HNSCC tumor samples through high-throughput sequencing and other array technologies. Samples with genomic amplification (red), homozygous deletion (blue), and/or mutation (green) are presented in the OncoPrint as individual bars or square dots. Only those samples with genetic alterations in the PI3K/Akt/mTOR pathway are presented $(183 / 279$ tumors $=66 \%$ of cases $)$. Percentages reflect the frequency with which samples express any of the three alterations reported in a given gene. Copy number variations are putative. PI3K catalytic subunit alpha isoform (PIK3CA); epidermal growth factor receptor (EGFR); eIF-4E binding protein 1 (EIF4EBP1); ribosomal protein S6 kinase (RPS6KB); Harvey rat sacrcoma virus oncogene (HRAS); protein kinase B (AKT); 3-phosphoinositide dependent protein kinase 1 (PDK1); phosphatase and tensin homolog (PTEN); tuberous sclerosis (TSC); Ras-homolog enriched in brain (RHEB); mammalian target of rapamycin (mTOR) 
p110- $\gamma$ in myeloid cells (Koyasu, 2003; Vanhaesebroeck et al, 2005). As such, both $\mathrm{p} 110-\delta$ and $\mathrm{p} 110-\gamma$ are crucial for promoting inflammation in the cancer microenvironment. Although most of the PI3K pathway-directed anti-cancer therapies have aimed at $\mathrm{p} 110-\alpha$ suppression, isoform-specific inhibition of $\mathrm{p} 110-\delta$ or $-\gamma$ also attenuates dysregulated inflammatory and immunosuppressive responses and may have an improved safety profile (Rommel et al, 2007; Fruman and Rommel, 2011; Schmid et al, 2011).

Dysregulated inflammatory signaling mediates angiogenesis, a critical process enabling tumor growth and spread. Angiogenesis is promoted by the secretion of cytokines such as vascular endothelial growth factor (VEGF), basic fibroblast growth factor (b-FGF), and interleukin-8 (IL-8) by tumor cells and associated myeloid lineage infiltrating cells. PI3K is activated downstream of the receptors for these signaling molecules and acts as a master regulator of angiogenesis and associated cytokine release (Yuan and Cantley, 2008). mTORC1 phosphorylation of eIF-4E facilitates tumor progression by increasing b-FGF and VEGF and increases risk for second primary in histologically cancer-free surgical margins (Nathan et al, 1999). While increased VEGF is associated with poor prognosis in HNSCC (Luangdilok et al, 2011), we have shown that pharmacologic inhibition of PI3K reduces phosphorylation of Akt in HNSCC cell lines, thereby blocking the secretion of VEGF and IL-8, even under epidermal growth factor (Bancroft et al, 2002) or hepatocyte growth factor stimulation (Dong et al, 2001a). In preclinical mouse studies, constitutive Akt activity causes abnormal vascular patterning (Hamada et al, 2005), and conditional class IA PI3K knockout compromises vascular integrity, limiting tumor size (Graupera et al, 2008; Yuan et al, 2008).

Although the PI3K/Akt/mTOR pathway enables vascular formation and growth factor delivery to tumors, it also confers a selective growth advantage and survival in conditions of nutrient deprivation. Normal cells live within 100-200 $\mu \mathrm{m}$ of a capillary bed, the diffusion limit of oxygen (Baish et al, 2011). Malignant cells with aberrations in PIK3CA, PTEN, or MTOR, however, are able to continue proliferating in hypoxic conditions outside of this range because of a modified cellular response to hypoxic stress, nutrient sensing, insulin signaling, and glucose uptake (Abraham, 2004; Kalaany and Sabatini, 2009; Kang et al, 2013; Vogelstein et al, 2013). Akt also promotes cell survival by attenuating pro-apoptotic factors, BAD, BAX, procaspase-9, and FOXO (Hennessy et al, 2005; Engelman et al, 2006).

Tumor outgrowths as a result of aberrant $\mathrm{PI} 3 \mathrm{~K} / \mathrm{Akt} / \mathrm{mTOR}$ signaling can subsequently lead to invasion (Samuels et al, 2005). Mechanistically, PI3K oncogenic disruption through PTEN loss disturbs membrane polarity and leads to epithelial-to-mesenchymal transition (Martin-Belmonte and Mostov, 2008), a key event causing invasion. 3q26 (PIK3CA locus) copy number gain and amplification is much more frequent in invasive carcinoma and high-grade dysplasia than in low-grade dysplasia (Woenckhaus et al, 2002). Late-stage HNSCC lesions also express higher levels of PI3K p110 $\alpha$ mRNA and protein (Woenckhaus et al, 2002), lower levels of PTEN (Squarize et al, 2002, 2013), and more simultaneous mutations in multiple PI3K pathway genes (Lui et al, 2013). In addition, increased phospho-Akt and phospho-S6 expressions have been correlated with HNSCC progression (Amornphimoltham et al, 2004; Molinolo et al, 2007). This suggests that disruption of any number of components in the PI3K pathway might act as an oncogenic switch leading to invasion. Once invasion has occurred, PI3K-PTEN interplay regulates chemotaxis and intravasation of cells into endothelial networks (Kolsch et al, 2008). Consequently, the capacity of the PI3K/Akt/mTOR pathway to concurrently regulate the processes of angiogenesis, cell motility, and invasion also gives it solid footing for contributions to metastasis.

Accordingly, lymph node metastases are directly associated with PIK3CA gain and mutation (Fenic et al, 2007). Because metastasis is the leading cause of death for patients with solid tumors, PI3K activation portends a worse prognosis. Indeed, two independent studies of HNSCC show that 3q26 gain (PIK3CA locus) can predict poor clinical outcome for patients with early disease tumors that have not yet metastasized (Redon et al, 2001; Suda et al, 2012). Reduced PTEN expression is a separate prognostic indicator of poor clinical outcome (Lee et al, 2001). Additionally, mTOR blockade is able to diminish lymphangiogenesis and cervical lymph node spread, thereby increasing survival (Patel et al, 2011). Because PI3K, Akt, and mTOR activation and PTEN inactivation are all independently associated with adverse outcome in HNSCC (Nathan et al, 2004; Massarelli et al, 2005; Molinolo et al, 2009), they serve as logical targets in clinical trials.

\section{PI3K/Akt/mTOR interactions with other signaling molecules}

TP53 is one of the best-studied and most frequently deleted or mutated tumor suppressor genes. Inactivation of p53 can occur through physical association with murine double minute 2 homolog (MDM2), which results in centrosome hyperamplification, chromosomal instability, and aberrant mitosis (Carroll et al, 1999). PI3K phosphorylation of Akt activates MDM2 by translocating it from the cytoplasm to the nucleus, thereby diminishing cellular levels of p53 (Mayo and Donner, 2001). Concurrent inactivating mutations in TP53 and activating abnormalities in $P I K 3 C A$ are uncommon in cancer, implying that they are often mutually exclusive and independent promoters of malignancy. In HNSCC, PI3KCA activation confers resistance to p53-induced apoptosis, while p53-mediated apoptosis involves transcriptional inhibition of PIK3CA (Singh et al, 2002). We have shown that treatment with the PI3K/mTOR inhibitor, PF-04691502 (PF-502), induces apoptosis and expression of wild-type p53 in two separate in vivo models of HNSCC (Herzog et al, 2013). We have also provided evidence that Akt inhibition reverses the direct suppression of p53 by transcriptional and post-translational mechanisms (Friedman et al, 2013). In glioma and endothelial cells, PI3K inhibition has also been reported to increase p53 transactivation and transcription of its target genes (Su et al, 2003). Furthermore, p53 is able to induce PTEN, favoring cell death in malignancy (Mayo and Donner, 2002). Other studies have evinced that 
mTOR signaling contributes to p53 inactivation through IGF-1R-mediated upregulation of MDM2 (Du et al, 2013), and the use of the mTOR inhibitor, rapamycin, is able to prevent oral cancer progression in a $\mathrm{K}$-ras/p53 double-knockout mouse model (Raimondi et al, 2009). Thus, therapies targeting $\mathrm{PI} 3 \mathrm{~K} / \mathrm{mTOR}$ may be doubly effective because of their capacity to both limit PI3K/Akt/ mTOR-mediated growth and survival and intensify p53mediated apoptosis.

In contrast to loss of p53 as a mechanism for evading apoptosis, overactivity of the transcription factor, NF- $\kappa \mathrm{B}$, is another important anti-apoptotic and prosurvival event in HNSCC (Van Waes, 2007). We have compiled a large body of evidence showing that $\mathrm{NF}-\kappa \mathrm{B}$ regulates the gene expression and secretion of multiple cytokines and chemokines that favor tumor progression (Chen et al, 1998, 1999; Duffey et al, 1999; Loukinova et al, 2000; Dong et al, 2001b; Allen et al, 2007). Activation and nuclear translocation of NF- $\kappa \mathrm{B}$ occurs primarily through phosphorylation of inhibitor- $\kappa \mathrm{B}$ kinases (IKK) (Van Waes et al, 2007; Nottingham et al, 2013), which can be phosphorylated downstream of active PI3K/Akt (Ozes et al, 1999; Romashkova and Makarov, 1999; Yang et al, 2001; Hutti et al, 2012) in a cell-type-specific manner (Gustin et al, 2004). Accordingly, we have shown that the PI3K inhibitor, LY-294002, is able to reduce both constitutive and inducible NF- $\kappa \mathrm{B}$ activity in HNSCC (Bancroft et al, 2002). Furthermore, rapamycin has also been shown to inhibit IKK activity, as the stimulation of IKK through Akt requires the interaction of the mTOR-associated protein, raptor, with IKK (Dan et al, 2008). While the mechanisms of interaction between the PI3K/Akt/mTOR and $\mathrm{NF}-\kappa \mathrm{B}$ pathways have been elucidated in many cancers, it remains to be studied further in HNSCC.

The PI3K/Akt/mTOR signaling route is also activated in concert with the Ras/Raf (MAPK kinase kinase)/ MAPK pathway downstream of EGFR. Although the contributions of these signaling pathways to malignancy are often independent of EGFR overactivity, recent evidence indicates that MAPK activity is differentially affected by the EGFR-dependent PI3K/Akt/mTOR axis. Many studies have shown that through various feedback loops or resistance mechanisms, inhibition of one pathway downstream of EGFR or IGF-1R causes compensatory signaling through other parallel pathways (Carracedo et al, 2008; Pernas et al, 2009; Ercan et al, 2012; Limesand et al, 2013). The pleiotropy and resistance to therapy of downstream EGFR signaling has led to preclinical and clinical trials of combinations of EGFR, PI3K, mTOR, MAPK kinase kinase, effector of Ras (RAF), and MAPK kinase (MEK)/ERK inhibitors. Although the interactions between the PI3K/Akt/mTOR axis and $553, \mathrm{NF}-\kappa \mathrm{B}$, and MAPK signaling pathways are perhaps the most studied, this is by no means an exhaustive list of its interactions. The EGFR/PI3K/Akt/mTOR axis has also been shown to be modified in HNSCC in response to the modulation of transforming growth factor beta (TGF- $\beta$ ) (Bian et al, 2012), signal transducer and activator of transcription 3 (STAT3) (Lee et al, 2008; Sen et al, 2012), and Wnt signaling (Kavitha et al, 2013), among others.

\section{PI3K/Akt/mTOR inhibitors in clinical studies}

The summary of currently ongoing clinical trials using PI3K pathway inhibitors for head and neck cancer is presented in Table 1. BKM120, a pan-isoform PI3K inhibitor which is furthest along in development, is currently in a phase III trial for breast cancer (NCT01633060). Several studies have been initiated to select for patients with HNSCC, including a phase II trial using BKM120 as a single agent and a phase I/II study combining BKM120 with cetuximab. The orally available, irreversible pan-isoform PI3K inhibitor PX-866 has also moved into phase II trials for HNSCC. Although showing limited effect as a single agent in solid tumors including HNSCC (Hong et al, 2012), phase I/II trials combining PX-866 with cetuximab and docetaxel have been initiated in patients with HNSCC and may provide further insight into the efficacy of this drug.

Several isoform-specific PI3K inhibitors are currently in clinical trials, offering the potential benefit of improved target selectivity with fewer off-target side effects. Of these, only BYL719, a PI3K $\alpha$-specific inhibitor, has been applied to patients with HNSCC. The phase I trial on this drug was the first to selectively enroll patients with advanced solid tumors with prescreened mutations or amplifications of $P I K 3 C A$. In the dose escalation portion, eight patients including those with oral cancers showed prolonged disease stabilization lasting $\geq 4$ months (Juric et al, 2012), while the dose expansion study that followed reported a partial response in 7/39 patients, one of which had HNSCC (Gonzalez-Angulo, 2013). The safety profile for BYL719 was similar to pan-PI3K inhibitors studied, with the most common adverse effects including hyperglycemia, nausea, and GI toxicities. Based on the encouraging results from this initial trial, BYL719 is currently being evaluated in combination with cetuximab in a phase $\mathrm{Ib} / \mathrm{II}$ trial in patients with HNSCC.

Previously, the Akt inhibitor perifosine showed promising results in preclinical studies, but when moved to phase II clinical trials in HNSCC, it failed to show any antitumor effect (Argiris et al, 2006; Hideshima et al, 2006). More recently, a newer Akt inhibitor MK-2206 has shown synergistic activity with paclitaxel in preclinical models and phase I trials of HNSCC (Ahmed et al, 2013). It is currently being evaluated in phase II trials as a single agent in recurrent or metastatic HNSCC and may prove to be more effective than previous agents.

Rapamycin, the first mTOR inhibitor, targets mTOR exclusively and has shown anti-tumor activity in preclinical models (Amornphimoltham et al, 2005). The first clinical trial of rapamycin as a single agent in HNSCC is ongoing in phase I/II. Several rapamycin analogues have been developed, including temsirolimus (CCI-779) and everolimus (RAD001). Temsirolimus, after showing initial safety and strong inhibition of mTOR targets S6 and 4EBP1 in HNSCC patient tumors (Ekshyyan et al, 2010), has moved to phase II trials in HNSCC as a single agent, in combination with carboplatin and paclitaxel or with cetuximab. Meanwhile, everolimus is also being evaluated extensively in HNSCC, with two phase I trials that have recently completed. In the first trial, combining everolimus 
with cisplatin and docetaxel as induction therapy for radiation, 2-year overall survival rate was $91 \%$ and progression-free survival rate at 2 years was $76.6 \%$ (Fury et al, 2013b). In the second trial, everolimus was given with cisplatin and concurrent radiation, showing a 2-year overall survival rate of $92 \%$ and 2-year progression-free survival rate of $85 \%$ (Fury et al, 2013a). The most impressive response, however, has come from the ongoing phase I-II trials of everolimus in combination with carboplatin and paclitaxel as induction therapy in patients with unresectable locally advanced HNSCC. Recently presented results showed a $2.6 \%$ complete response, $76.3 \%$ partial response, as well as $21 \%$ stable disease in the 38 evaluable patients (Raymond et al, 2013). Everolimus continues to be investigated alone and in combinations in patients with HNSCC in five additional phase I-II trials (Table 1).

An important drawback in selectively inhibiting mTOR is the negative feedback loop that exists, in which S6K phosphorylates and blocks insulin receptor substrate 1 (IRS1), leading to the activation of PI3K and subsequent tumor growth (O'Reilly et al, 2006; Huang and Manning, 2009). To overcome this drawback, there is growing interest in the development of dual PI3K-mTOR inhibitors that can target the pathway at two points simultaneously. Dual PI3K-mTOR inhibitors that have shown promising results in preclinical studies of HNSCC include the orally available PF-502 (Herzog et al, 2013) and intravenously administered PF-05212384 (PF-384). Preliminary results from a phase I trial of PF-502, which is currently open to HNSCC, but to date only includes other advanced solid tumors such as non-small-cell lung carcinoma (NSCLC) and colorectal carcinoma, have shown no objective tumor reduction, but stable disease $\geq 16$ weeks in approximately $16 \%$ of patients (LoRusso et al, 2011). Similarly, approximately $25 \%$ of patients with solid tumors including NSCLC given weekly PF-384 as a single agent achieved stable disease $\geq 16$ weeks, although no objective tumor reduction was observed (Tabernero et al, 2011). Additional phase I trials of PF-384 in combination with docetaxel, cisplatin, and dacomitinib (EGFR inhibitor), as well as irinotecan (topoisomerase 1 inhibitor) and PD-901 (MEK inhibitor), may prove to have greater anti-tumor effects than single agents alone in HNSCC.

\section{Conclusion and future directions}

Following these initial clinical trials of agents targeting the PI3K pathway, several key questions remain. Additional studies will necessitate decision making about the most biologically active dose for each drug, the ideal method of administration, and the acceptance of adverse events including on-target effects such as hyperglycemia. It remains to be determined which class of agents targeting PI3K, mTOR, or Akt will be most effective in HNSCC, and whether there are factors that would make one class superior to the other in specific cases. Several clinical trials have retroactively analyzed PIK3CA mutation status in patient samples, while few have limited enrollment to patients with known PI3K pathway mutations. There has been some evidence that preselected patients with mutations in PI3K have better response to treatment, revealing improved outcomes compared to nonselective trials. Prescreening for molecular alterations has proven beneficial in preclinical studies as well, as it has uncovered critical mechanistic information regarding sensitivity or resistance and effects on other pathways. PI3K pathway cross-talk with other signaling routes, such as $\mathrm{p} 53$, NF- $\kappa \mathrm{B}$, and MAPK, should be investigated more extensively when designing future clinical trials. As largescale screening protocols for molecular alterations become more prevalent in drug development trials, the feasibility of translating genetic information about the PI3K/Akt/ mTOR axis to the clinic increases. Ultimately, this will allow clinicians to tailor treatment to an individual molecular profile and improve patient care.

\section{Acknowledgements}

R.V., S.M., and D.E. were supported through the National Institutes of Health (NIH) Medical Research Scholars Program, a public-private partnership supported jointly by the NIH and generous contributions to the foundation for the NIH from Pfizer Inc, The Leona M. and Harry B. Helmsley Charitable Trust, and the Howard Hughes Medical Institute, as well as other private donors. For a complete list, please visit the foundation website at http://fnih.org/work/education-training-0/medical-research-scholarsprogram. Z.C. and C.V. were supported by NIDCD intramural project ZIA-DC-000016.

\section{Author contributions}

R. Vander Broek, S. Mohan, D.F. Eytan, Z. Chen, and C. Van Waes contributed to the conception, design, drafting, and editing of the manuscript, tables, and figures.

\section{References}

Abraham RT (2004). mTOR as a positive regulator of tumor cell responses to hypoxia. Curr Top Microbiol Immunol 279: 299-319.

Agrawal N, Frederick MJ, Pickering CR et al (2011). Exome sequencing of head and neck squamous cell carcinoma reveals inactivating mutations in NOTCH1. Science 333: 1154-1157.

Ahmed O, Kuo WL, Nagilla M et al (2013). Synergy with combination of AKT inhibitor (MK-2206) and paclitaxel in head and neck squamous cell carcinoma. J Clin Oncol 31, Abstract e13532.

Allen C, Duffy S, Teknos T et al (2007). Nuclear factor-kappaBrelated serum factors as longitudinal biomarkers of response and survival in advanced oropharyngeal carcinoma. Clin Cancer Res 13: 3182-3190.

Amornphimoltham P, Sriuranpong V, Patel V et al (2004). Persistent activation of the Akt pathway in head and neck squamous cell carcinoma: a potential target for UCN-01. Clin Cancer Res 10: 4029-4037.

Amornphimoltham P, Patel V, Sodhi A et al (2005). Mammalian target of rapamycin, a molecular target in squamous cell carcinomas of the head and neck. Cancer Res 65: 9953-9961.

Argiris A, Cohen E, Karrison T et al (2006). A phase II trial of perifosine, an oral alkylphospholipid, in recurrent or metastatic head and neck cancer. Cancer Biol Ther 5: 766-770.

Baish JW, Stylianopoulos T, Lanning RM et al (2011). Scaling rules for diffusive drug delivery in tumor and normal tissues. Proc Natl Acad Sci USA 108: 1799-1803. 
Bancroft CC, Chen Z, Yeh J et al (2002). Effects of pharmacologic antagonists of epidermal growth factor receptor, PI3K and MEK signal kinases on NF-kappaB and AP-1 activation and IL-8 and VEGF expression in human head and neck squamous cell carcinoma lines. Int $J$ Cancer 99: 538-548.

Bellacosa A, Testa JR, Staal SP, Tsichlis PN (1991). A retroviral oncogene, akt, encoding a serine-threonine kinase containing an SH2-like region. Science 254: 274-277.

Bhaskar PT, Hay N (2007). The two TORCs and Akt. Dev Cell 12: 487-502.

Bian Y, Hall B, Sun ZJ et al (2012). Loss of TGF-beta signaling and PTEN promotes head and neck squamous cell carcinoma through cellular senescence evasion and cancer-related inflammation. Oncogene 31: 3322-3332.

Carracedo A, Ma L, Teruya-Feldstein J et al (2008). Inhibition of mTORC1 leads to MAPK pathway activation through a PI3K-dependent feedback loop in human cancer. J Clin Investig 118: 3065-3074.

Carroll PE, Okuda M, Horn HF et al (1999). Centrosome hyperamplification in human cancer: chromosome instability induced by p53 mutation and/or Mdm2 overexpression. Oncogene 18: 1935-1944.

Chen Z, Colon I, Ortiz N et al (1998). Effects of interleukin1alpha, interleukin-1 receptor antagonist, and neutralizing antibody on proinflammatory cytokine expression by human squamous cell carcinoma lines. Cancer Res 58: 3668-3676.

Chen Z, Malhotra PS, Thomas GR et al (1999). Expression of proinflammatory and proangiogenic cytokines in patients with head and neck cancer. Clin Cancer Res 5: 1369-1379.

Cohen Y, Goldenberg-Cohen N, Shalmon B et al (2011). Mutational analysis of PTEN/PIK3CA/AKT pathway in oral squamous cell carcinoma. Oral Oncol 47: 946-950.

Courtney KD, Corcoran RB, Engelman JA (2010). The PI3K pathway as drug target in human cancer. J Clin Oncol 28: 1075-1083.

Dan HC, Cooper MJ, Cogswell PC, Duncan JA, Ting JP, Baldwin AS (2008). Akt-dependent regulation of NF- $\{$ kappa $\}$ B is controlled by mTOR and Raptor in association with IKK. Genes Dev 22: 1490-1500.

Di Maira G, Salvi M, Arrigoni G et al (2005). Protein kinase CK2 phosphorylates and upregulates Akt/PKB. Cell Death Differ 12: 668-677.

Domin J, Waterfield MD (1997). Using structure to define the function of phosphoinositide 3-kinase family members. FEBS Lett 410: 91-95.

Dong G, Chen Z, Li ZY, Yeh NT, Bancroft CC, Van Waes C (2001a). Hepatocyte growth factor/scatter factor-induced activation of MEK and PI3K signal pathways contributes to expression of proangiogenic cytokines interleukin-8 and vascular endothelial growth factor in head and neck squamous cell carcinoma. Cancer Res 61: 5911-5918.

Dong G, Loukinova E, Chen Z et al (2001b). Molecular profiling of transformed and metastatic murine squamous carcinoma cells by differential display and cDNA microarray reveals altered expression of multiple genes related to growth, apoptosis, angiogenesis, and the NF-kappaB signal pathway. Cancer Res 61: 4797-4808.

Du W, Yi Y, Zhang H et al (2013). Rapamycin inhibits IGF-1mediated up-regulation of MDM2 and sensitizes cancer cells to chemotherapy. PLOS ONE 8: e63179.

Duffey DC, Chen Z, Dong G et al (1999). Expression of a dominant-negative mutant inhibitor-kappaBalpha of nuclear factorkappaB in human head and neck squamous cell carcinoma inhibits survival, proinflammatory cytokine expression, and tumor growth in vivo. Cancer Res 59: 3468-3474.
Ekshyyan O, Mills GM, Lian T et al (2010). Pharmacodynamic evaluation of temsirolimus in patients with newly diagnosed advanced-stage head and neck squamous cell carcinoma. Head Neck 32: 1619-1628.

Engelman JA (2009). Targeting PI3K signalling in cancer: opportunities, challenges and limitations. Nat Rev Cancer 9: 550-562.

Engelman JA, Luo J, Cantley LC (2006). The evolution of phosphatidylinositol 3-kinases as regulators of growth and metabolism. Nat Rev Genet 7: 606-619.

Ercan D, Xu C, Yanagita M et al (2012). Reactivation of ERK signaling causes resistance to EGFR kinase inhibitors. Cancer Discov 2: 934-947.

Fenic I, Steger K, Gruber C, Arens C, Woenckhaus J (2007). Analysis of PIK3CA and Akt/protein kinase B in head and neck squamous cell carcinoma. Oncol Rep 18: 253-259.

Freudlsperger C, Burnett JR, Friedman JA, Kannabiran VR, Chen Z, Van Waes C (2011). EGFR-PI3K-AKT-mTOR signaling in head and neck squamous cell carcinomas: attractive targets for molecular-oriented therapy. Expert Opin Ther Targets 15: 63-74.

Friedman JA, Wise SC, Hu M et al (2013). HSP90 inhibitor SNX5422/2112 targets the dysregulated signal and transcription factor network and malignant phenotype of head and neck squamous cell carcinoma. Transl Oncol 6: 429441.

Fruman DA, Rommel C (2011). PI3Kdelta inhibitors in cancer: rationale and serendipity merge in the clinic. Cancer Discov 1: $562-572$.

Fruman DA, Meyers RE, Cantley LC (1998). Phosphoinositide kinases. Annu Rev Biochem 67: 481-507.

Fury MG, Lee NY, Sherman E et al (2013a). A Phase 1 Study of Everolimus + Weekly Cisplatin + Intensity Modulated Radiation Therapy in Head-and-Neck Cancer. Int J Radiat Oncol Biol Phys 87: 479-486.

Fury MG, Sherman E, Ho AL et al (2013b). A phase 1 study of everolimus plus docetaxel plus cisplatin as induction chemotherapy for patients with locally and/or regionally advanced head and neck cancer. Cancer 119: 1823-1831.

Gillison ML, Koch WM, Capone RB et al (2000). Evidence for a causal association between human papillomavirus and a subset of head and neck cancers. J Natl Cancer Inst 92: 709-720.

Gingras AC, Raught B, Sonenberg N (1999). eIF4 initiation factors: effectors of mRNA recruitment to ribosomes and regulators of translation. Annu Rev Biochem 68: 913-963.

Gonzalez-Angulo A (2013). Safety, pharmacokinetics, and preliminary activity of the $\alpha$-specific PI3K inhibitor BYL719: results from the first-in-human study. $J$ Clin Oncol 31, Abstract 2531.

Grandis JR, Hayes DN, El-Naggar AK, and The Cancer Genome Atlas Group (2012). Comprehensive genomic characterization of squamous cell carcinoma of the head and neck. TCGA 2nd Annual Scientific Symposium: 32

Graupera M, Guillermet-Guibert J, Foukas LC et al (2008). Angiogenesis selectively requires the p110alpha isoform of PI3K to control endothelial cell migration. Nature 453: 662-666.

Grivennikov SI, Greten FR, Karin M (2010). Immunity, inflammation, and cancer. Cell 140: 883-899.

Gustin JA, Ozes ON, Akca H et al (2004). Cell type-specific expression of the IkappaB kinases determines the significance of phosphatidylinositol 3-kinase/Akt signaling to NF-kappa B activation. J Biol Chem 279: 1615-1620.

Hamada K, Sasaki T, Koni PA et al (2005). The PTEN/PI3K pathway governs normal vascular development and tumor angiogenesis. Genes Dev 19: 2054-2065. 
Hayes DN, Grandis JR, El-Naggar AK (2013). Comprehensive genomic characterization of squamous cell carcinoma of the head and neck in the Cancer Genome Atlas. American Association for Cancer Research Annual Meeting, Washington, DC: Abstract 1117.

Hennessy BT, Smith DL, Ram PT, Lu Y, Mills GB (2005). Exploiting the PI3K/AKT pathway for cancer drug discovery. Nat Rev Drug Discovery 4: 988-1004.

Herzog A, Bian Y, Vander Broek R et al (2013). PI3K/mTOR Inhibitor PF-04691502 Antitumor Activity Is Enhanced with Induction of Wild-Type TP53 in Human Xenograft and Murine Knockout Models of Head and Neck Cancer. Clin Cancer Res 19: 3808-3819.

Hideshima T, Catley L, Yasui H et al (2006). Perifosine, an oral bioactive novel alkylphospholipid, inhibits Akt and induces in vitro and in vivo cytotoxicity in human multiple myeloma cells. Blood 107: 4053-4062.

Hong DS, Bowles DW, Falchook GS et al (2012). A multicenter phase I trial of PX-866, an oral irreversible phosphatidylinositol 3-kinase inhibitor, in patients with advanced solid tumors. Clin Cancer Res 18: 4173-4182.

Huang J, Manning BD (2009). A complex interplay between Akt, TSC2 and the two mTOR complexes. Biochem Soc Trans 37: 217-222.

Hutti JE, Pfefferle AD, Russell SC, Sircar M, Perou CM, Baldwin AS (2012). Oncogenic PI3K mutations lead to NF-kappaBdependent cytokine expression following growth factor deprivation. Cancer Res 72: 3260-3269.

Iglesias-Bartolome R, Martin D, Gutkind JS (2013). Exploiting the head and neck cancer oncogenome: widespread PI3KmTOR pathway alterations and novel molecular targets. Cancer Discov 3: 722-725.

Inoki K, Corradetti MN, Guan KL (2005). Dysregulation of the TSC-mTOR pathway in human disease. Nat Genet 37: $19-24$.

Juric D, Rodon J, Gonzalez-Angulo AM et al (2012). BYL719, a next generation PI3K alpha specific inhibitor: Preliminary safety, $P K$, and efficacy results from the first-in-human study. Proceedings of the 103rd Annual Meeting of the American Association for Cancer Research: Abstract CT-01.

Kalaany NY, Sabatini DM (2009). Tumours with PI3K activation are resistant to dietary restriction. Nature 458: 725-731.

Kalyankrishna S, Grandis JR (2006). Epidermal growth factor receptor biology in head and neck cancer. J Clin Oncol 24: 2666-2672.

Kang SA, Pacold ME, Cervantes CL et al (2013). mTORC1 phosphorylation sites encode their sensitivity to starvation and rapamycin. Science 341: 1236566.

Katso R, Okkenhaug K, Ahmadi K, White S, Timms J, Waterfield MD (2001). Cellular function of phosphoinositide 3-kinases: implications for development, homeostasis, and cancer. Annu Rev Cell Dev Biol 17: 615-675.

Kavitha K, Kowshik J, Kishore TK, Baba AB, Nagini S (2013). Astaxanthin inhibits NF-kappaB and Wnt/betacatenin signaling pathways via inactivation of Erk/MAPK and PI3K/Akt to induce intrinsic apoptosis in a hamster model of oral cancer. Biochim Biophys Acta 1830: 4433-4444.

Keysar SB, Astling DP, Anderson RT et al (2013). A patient tumor transplant model of squamous cell cancer identifies PI3K inhibitors as candidate therapeutics in defined molecular bins. Molecular oncology 7: 776-790.

Kolsch V, Charest PG, Firtel RA (2008). The regulation of cell motility and chemotaxis by phospholipid signaling. J Cell Sci 121: 551-559.

Koyasu S (2003). The role of PI3K in immune cells. Nat Immunol 4: 313-319.
Kozaki K, Imoto I, Pimkhaokham A et al (2006). PIK3CA mutation is an oncogenic aberration at advanced stages of oral squamous cell carcinoma. Cancer Sci 97: 1351-1358.

Lee JI, Soria JC, Hassan KA et al (2001). Loss of PTEN expression as a prognostic marker for tongue cancer. Arch Otolaryngol Head Neck Surg 127: 1441-1445.

Lee TL, Yeh J, Friedman J et al (2008). A signal network involving coactivated NF-kappaB and STAT3 and altered p53 modulates BAX/BCL-XL expression and promotes cell survival of head and neck squamous cell carcinomas. Int $J$ Cancer 122: 1987-1998.

Leemans CR, Braakhuis BJ, Brakenhoff RH (2011). The molecular biology of head and neck cancer. Nat Rev Cancer 11: 9-22.

Li Y, Corradetti MN, Inoki K, Guan KL (2004). TSC2: filling the GAP in the mTOR signaling pathway. Trends Biochem Sci 29: $32-38$.

Limesand KH, Chibly AM, Fribley A (2013). Impact of targeting insulin-like growth factor signaling in head and neck cancers. Growth Horm IGF Res 23: 135-140.

Liu P, Cheng H, Roberts TM, Zhao JJ (2009). Targeting the phosphoinositide 3-kinase pathway in cancer. Nat Rev Drug Discovery 8: 627-644.

LoRusso P, Britten C, Millham R et al (2011). First-in-patient study of PF-04691502, a small molecule intravenous dual inhibitor of PI3K and mTOR in patients with advanced cancer: update on safety, efficacy, and pharmacology. AACRNCI-EORTC International Conference: Molecular Targets and Cancer Therapeutics: Abstract B163.

Loukinova E, Dong G, Enamorado-Ayalya I et al (2000). Growth regulated oncogene-alpha expression by murine squamous cell carcinoma promotes tumor growth, metastasis, leukocyte infiltration and angiogenesis by a host CXC receptor-2 dependent mechanism. Oncogene 19: 3477-3486.

Lu C, Mi LZ, Schurpf T, Walz T, Springer TA (2012). Mechanisms for kinase-mediated dimerization of the epidermal growth factor receptor. J Biol Chem 287: 38244-38253.

Luangdilok S, Box C, Harrington K, Rhys-Evans P, Eccles S (2011). MAPK and PI3K signalling differentially regulate angiogenic and lymphangiogenic cytokine secretion in squamous cell carcinoma of the head and neck. Eur J Cancer 47: 520-529.

Lui VW, Hedberg ML, Li H et al (2013). Frequent mutation of the PI3K pathway in head and neck cancer defines predictive biomarkers. Cancer Discov 3: 761-769.

Manning BD, Cantley LC (2007). AKT/PKB signaling: navigating downstream. Cell 129: 1261-1274.

Martin-Belmonte F, Mostov K (2008). Regulation of cell polarity during epithelial morphogenesis. Curr Opin Cell Biol 20: 227-234.

Massarelli E, Liu DD, Lee JJ et al (2005). Akt activation correlates with adverse outcome in tongue cancer. Cancer 104: 2430-2436.

Mayo LD, Donner DB (2001). A phosphatidylinositol 3-kinase/ Akt pathway promotes translocation of Mdm2 from the cytoplasm to the nucleus. Proc Natl Acad Sci USA 98: $11598-11603$.

Mayo LD, Donner DB (2002). The PTEN, Mdm2, p53 tumor suppressor-oncoprotein network. Trends Biochem Sci 27: 462-467.

McBride SM, Rothenberg SM, Faquin WC et al (2013). Mutation frequency in 15 common cancer genes in high-risk head and neck squamous cell carcinoma (HNSCC). Head Neck [Epub ahead of print]. PMID 23852799.

Meyuhas O (2000). Synthesis of the translational apparatus is regulated at the translational level. Euro J Bioche FEBS 267: 6321-6330. 
Molinolo AA, Hewitt SM, Amornphimoltham P et al (2007). Dissecting the Akt/mammalian target of rapamycin signaling network: emerging results from the head and neck cancer tissue array initiative. Clin Cancer Res 13: 4964-4973.

Molinolo AA, Amornphimoltham P, Squarize CH, Castilho RM, Patel V, Gutkind JS (2009). Dysregulated molecular networks in head and neck carcinogenesis. Oral Oncol 45: 324-334.

Morris LG, Taylor BS, Bivona TG et al (2011). Genomic dissection of the epidermal growth factor receptor (EGFR)/PI3K pathway reveals frequent deletion of the EGFR phosphatase PTPRS in head and neck cancers. Proc Natl Acad Sci USA 108: 19024-19029.

Murugan AK, Hong NT, Fukui Y, Munirajan AK, Tsuchida N (2008). Oncogenic mutations of the PIK3CA gene in head and neck squamous cell carcinomas. Int J Oncol 32: 101-111.

Nathan CO, Franklin S, Abreo FW, Nassar R, De Benedetti A, Glass J (1999). Analysis of surgical margins with the molecular marker eIF4E: a prognostic factor in patients with head and neck cancer. J Clin Oncol 17: 2909-2914.

Nathan CO, Amirghahari N, Abreo F et al (2004). Overexpressed eIF4E is functionally active in surgical margins of head and neck cancer patients via activation of the Akt/mammalian target of rapamycin pathway. Clin Cancer Res 10: 5820-5827.

Nichols AC, Palma DA, Chow W et al (2013). High frequency of activating PIK3CA mutations in human papillomaviruspositive oropharyngeal cancer. JAMA Otolaryngol Head Neck Surg 139: 617-622.

Normanno N, De Luca A, Bianco C et al (2006). Epidermal growth factor receptor (EGFR) signaling in cancer. Gene 366: $2-16$.

Nottingham LK, Yan CH, Yang X et al (2013). Aberrant IKKalpha and IKKbeta cooperatively activate NF-kappaB and induce EGFR/AP1 signaling to promote survival and migration of head and neck cancer. Oncogene [Epub ahead of print]. PMID 23455325.

Okami K, Wu L, Riggins G et al (1998). Analysis of PTEN/ MMAC1 alterations in aerodigestive tract tumors. Cancer Res 58: 509-511.

O'Reilly KE, Rojo F, She QB et al (2006). mTOR inhibition induces upstream receptor tyrosine kinase signaling and activates Akt. Cancer Res 66: 1500-1508.

Ozes ON, Mayo LD, Gustin JA, Pfeffer SR, Pfeffer LM, Donner DB (1999). NF-kappaB activation by tumour necrosis factor requires the Akt serine-threonine kinase. Nature 401: 82-85.

Pan D, Dong J, Zhang Y, Gao X (2004). Tuberous sclerosis complex: from Drosophila to human disease. Trends Cell Biol 14: $78-85$.

Patel V, Marsh CA, Dorsam RT et al (2011). Decreased lymphangiogenesis and lymph node metastasis by mTOR inhibition in head and neck cancer. Cancer Res 71: 7103-7112.

Pernas FG, Allen CT, Winters ME et al (2009). Proteomic signatures of epidermal growth factor receptor and survival signal pathways correspond to gefitinib sensitivity in head and neck cancer. Clin Cancer Res 15: 2361-2372.

Pickering CR, Zhang J, Yoo SY et al (2013). Integrative genomic characterization of oral squamous cell carcinoma identifies frequent somatic drivers. Cancer Discov 3: 770-781.

Qiu W, Schönleben F, Li X et al (2006). PIK3CA mutations in head and neck squamous cell carcinoma. Clin Cancer Res 12: 1441-1446.

Raimondi AR, Molinolo A, Gutkind JS (2009). Rapamycin prevents early onset of tumorigenesis in an oral-specific K-ras and p53 two-hit carcinogenesis model. Cancer Res 69: 4159-4166.

Raymond E, Tourneau CL, Gatineau M et al (2013). CAPRA: Safety, efficacy, and translational biomarkers of weekly everolimus, carboplatin, and paclitaxel as induction therapy for locally advanced head and neck squamous cell carcinoma (HNSCC). J Clin Oncol 31, Abstract 6036.

Redon R, Muller D, Caulee K, Wanherdrick K, Abecassis J, du Manoir S (2001). A simple specific pattern of chromosomal aberrations at early stages of head and neck squamous cell carcinomas: PIK3CA but not p63 gene as a likely target of 3q26qter gains. Cancer Res 61: 4122-4129.

Rogers SJ, Harrington KJ, Rhys-Evans P, O-Charoenrat P, Eccles SA (2005). Biological significance of c-erbB family oncogenes in head and neck cancer. Cancer Metastasis Rev 24: 47-69.

Romashkova JA, Makarov SS (1999). NF-kappaB is a target of AKT in anti-apoptotic PDGF signalling. Nature 401: 86-90.

Rommel C, Camps M, Ji H (2007). PI3K delta and PI3K gamma: partners in crime in inflammation in rheumatoid arthritis and beyond? Nature reviews. Immunology 7: 191-201.

Samuels Y, Wang Z, Bardelli A et al (2004). High frequency of mutations of the PIK3CA gene in human cancers. Science 304: 554.

Samuels Y, Diaz LA Jr, Schmidt-Kittler O et al (2005). Mutant PIK3CA promotes cell growth and invasion of human cancer cells. Cancer Cell 7: 561-573.

Sarbassov DD, Guertin DA, Ali SM, Sabatini DM (2005). Phosphorylation and regulation of $\mathrm{Akt} / \mathrm{PKB}$ by the rictor-mTOR complex. Science 307: 1098-1101.

Scheid MP, Woodgett JR (2001). PKB/AKT: functional insights from genetic models. Nat Rev Mol Cell Biol 2: 760-768.

Schmid MC, Avraamides CJ, Dippold HC et al (2011). Receptor tyrosine kinases and TLR/IL1Rs unexpectedly activate myeloid cell PI3kgamma, a single convergent point promoting tumor inflammation and progression. Cancer Cell 19: 715-727.

Sen M, Joyce S, Panahandeh M et al (2012). Targeting Stat3 abrogates EGFR inhibitor resistance in cancer. Clin Cancer Res 18: 4986-4996.

Siegel R, Naishadham D, Jemal A (2013). Cancer statistics, 2013. CA Cancer J Clin 63: 11-30.

Singh B, Reddy PG, Goberdhan A et al (2002). p53 regulates cell survival by inhibiting PIK3CA in squamous cell carcinomas. Genes Dev 16: 984-93.

Squarize CH, Castilho RM, Santos Pinto D Jr (2002). Immunohistochemical evidence of PTEN in oral squamous cell carcinoma and its correlation with the histological malignancy grading system. J Oral Pathol Med 31: 379-384.

Squarize CH, Castilho RM, Abrahao AC, Molinolo A, Lingen MW, Gutkind JS (2013). PTEN deficiency contributes to the development and progression of head and neck cancer. Neoplasia 15: 461-471.

Stransky N, Egloff AM, Tward AD et al (2011). The mutational landscape of head and neck squamous cell carcinoma. Science 333: $1157-1160$.

Su JD, Mayo LD, Donner DB, Durden DL (2003). PTEN and phosphatidylinositol 3'-kinase inhibitors up-regulate p53 and block tumor-induced angiogenesis: evidence for an effect on the tumor and endothelial compartment. Cancer Res 63: 3585-3592.

Suda T, Hama T, Kondo S et al (2012). Copy number amplification of the PIK3CA gene is associated with poor prognosis in non-lymph node metastatic head and neck squamous cell carcinoma. BMC Cancer 12: 416.

Tabernero J, Bell-McGuinn K, Bendell J et al (2011). First-inpatient study of PF-05212384, a small molecule intravenous dual inhibitor of PI3K and mTOR in patients with advanced cancer: update on safety, efficacy, and pharmacology. AACRNCI-EORTC International Conference: Molecular Cancer Therapy: Abstract A167.

Van Waes C (2007). Nuclear factor-kappaB in development, prevention, and therapy of cancer. Clin Cancer Res 13: $1076-1082$. 
Van Waes C, Yu M, Nottingham L, Karin M (2007). InhibitorkappaB kinase in tumor promotion and suppression during progression of squamous cell carcinoma. Clin Cancer Res 13: 4956-4959.

Vanhaesebroeck B, Ali K, Bilancio A, Geering B, Foukas LC (2005). Signalling by PI3K isoforms: insights from genetargeted mice. Trends Biochem Sci 30: 194-204.

Vanhaesebroeck B, Guillermet-Guibert J, Graupera M, Bilanges B (2010). The emerging mechanisms of isoform-specific PI3K signalling. Nat Rev Mol Cell Biol 11: 329-341.

Vanhaesebroeck B, Stephens L, Hawkins P (2012). PI3K signalling: the path to discovery and understanding. Nat Rev Mol Cell Biol 13: 195-203.

Vivanco I, Sawyers CL (2002). The phosphatidylinositol 3-Kinase AKT pathway in human cancer. Nat Rev Cancer 2: 489-501.
Vogelstein B, Papadopoulos N, Velculescu VE, Zhou S, Diaz LA Jr, Kinzler KW (2013). Cancer genome landscapes. Science 339: 1546-1558.

Woenckhaus J, Steger K, Werner E et al (2002). Genomic gain of PIK3CA and increased expression of p110alpha are associated with progression of dysplasia into invasive squamous cell carcinoma. J Pathol 198: 335-342.

Yang CH, Murti A, Pfeffer SR, Kim JG, Donner DB, Pfeffer LM (2001). Interferon alpha/beta promotes cell survival by activating nuclear factor kappa B through phosphatidylinositol 3-kinase and Akt. J Biol Chem 276: 13756-13761.

Yuan TL, Cantley LC (2008). PI3K pathway alterations in cancer: variations on a theme. Oncogene 27: 5497-5510.

Yuan TL, Choi HS, Matsui A et al (2008). Class 1A PI3K regulates vessel integrity during development and tumorigenesis. Proc Natl Acad Sci USA 105: 9739-9744. 